\title{
First Confirmed Report of Powdery Mildew Caused by Erysiphe aquilegiae on Casuarina cunninghamiana in Argentina
}

\author{
Silvia Wolcan ${ }^{1}$, Sung-Eun Cho ${ }^{2}$, Ji-Hyun Park ${ }^{2}$ and Hyeon-Dong Shin ${ }^{2 *}$ \\ ${ }^{1}$ CIC - Centro de Investigaciones de Fitopatologia, Facultad de Ciencias Agrarias y Forestales, 60 y 119, 1900 La Plata, Argentina \\ ${ }^{2}$ Division of Environmental Science and Ecological Engineering, Korea University, Seoul 136-701, Korea
}

(Received on June 4, 2011; Accepted on January 27, 2012)

Casuarina cunninghamiana Miq. (Fam. Casuarinaceae) is native to Australia and was introduced to Argentina and used as a windbreak, shade tree and for ornamental purposes. In autumn 2009, the potted seedlings in the nursery of La Plata University were found to be infected with a powdery mildew. Symptoms first appeared as thin white colonies, which subsequently developed into an abundant growth on the leaves and young stems (Fig. 1A). The damage caused by the powdery mildew infection has been observed every year after this initial infection and was again confirmed in April, 2011. There have been a few reports on the presence of powdery mildew on Casuarina spp. (Mantz et al., 2008; Farr and Rossman, 2011). In all the reports, the pathogen was cited to be Oidium sp. Thus, the aim of this work was to identify the causal agent of the powdery mildew observed on casuarina in Argentina.

A detailed microscopic examination of a representative sample (KUS-F24744) deposited in Korea University was made to identify the pathogen. Conidiophores were cylindrical, 70-145 ×6-8.5 $\mu \mathrm{m}$, moderately flexuous to straight in foot-cells and produced conidia singly, followed by 2-3 cells (Fig. 1B-D). Appressoria were multilobed or moderately lobed (Fig. 1J). Conidia were oblongelliptical, 28-54 × 11-18 $\mu \mathrm{m}$, without conspicuous fibrosin bodies and produced germ tubes in the perihilar position (Fig. 1F-I). Firstformed conidia (Fig. 1E) were apically conical, basally subtruncate, and generally smaller than the secondary conidia. No chasmothecia were found but the above characteristics were consistent with the conidial state of Erysiphe aquilegiae DC. (Braun, 1987; Liberato

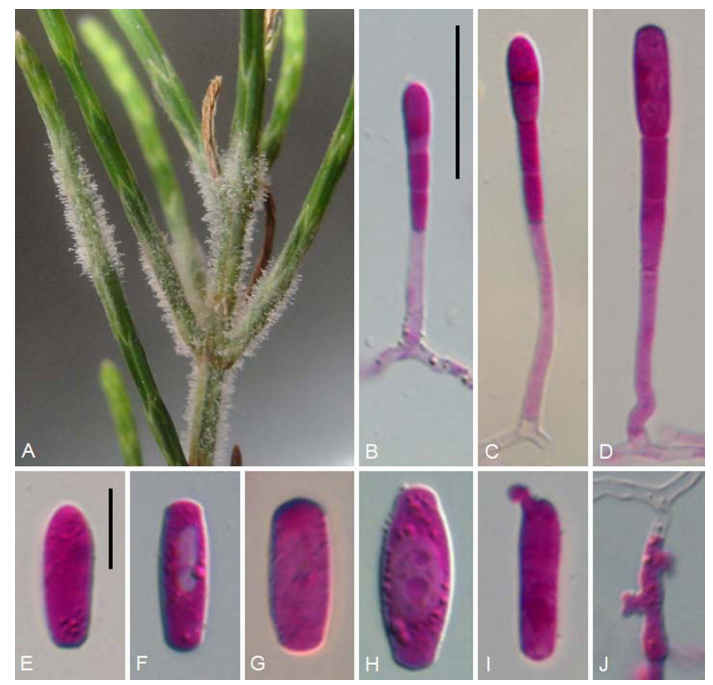

Fig. 1. Powdery mildew infections of Casuarina cunninghamiana by Erysiphe aquilegiae. (A) Close-up view of infected leaves. (B-C) Conidiophores with immature first-formed conidia. Note the conically rounded apex. (D) A conidiophore with an immature secondary conidium. Note the subtruncate apex. (E) A first-formed conidium. (F-H) Conidia. (I) Germinating conidium. (J) Hypha with multilobed appressoria. Each structure in B-J was stained with lactofuchsin. Bar $=50 \mu \mathrm{m}$ for B-D and $20 \mu \mathrm{m}$ for E-J. and Cunnington, 2006).

To confirm the identity of the causal fungus, the complete internal transcribed spacer (ITS) region of rDNA from KUS-F24744 was amplified using primers ITS5 and P3, and then directly sequenced. The resulting sequence of $553 \mathrm{bp}$ was deposited in GenBank (Accession No. JN003594). Phylogenetic analysis was performed using MEGA4 with the neighbor-joining method and the TajimaNei distance calculation. A comparison with the sequences available in the GenBank database revealed that the ITS sequence shared over $99 \%$ (552/553 bp) similarity with those of E. aquilegiae on several host genera of the Ranunculaceae (Fig. 2). Therefore, the sequence analysis verified that the pathogen was E. aquilegiae.

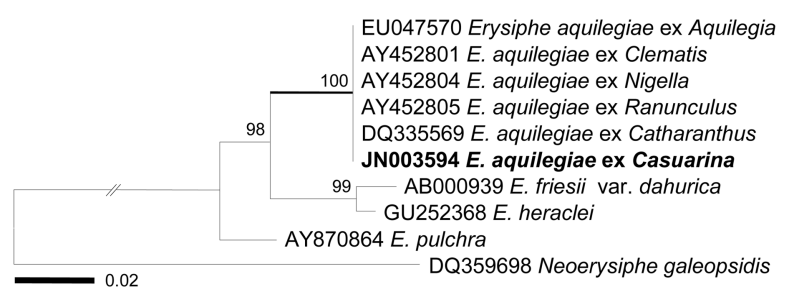

Fig. 2. Neighbor-joining tree showing the phylogenetic relationship among Erysiphe aquilegiae isolates inferred from the ITS rDNA region. Bootstrap values based on 1000 replications are indicated above the branches, and the scale bar represents 0.02 nucleotide substitutions per site.

Powdery mildew caused by $E$. aquilegiae has been shown to occur on plants belonging to the Ranunculaceae with one exception (Farr and Rossman, 2011). Catharanthus roseus (L.) G. Don, which belongs to the Apocynaceae, was found to be naturally infected by E. aquilegiae as demonstrated by morphological and molecular data (Liberato and Cunnington, 2006). To the best of our knowledge, this is the second report where E. aquilegiae was found on a host outside of the Ranunculaceae. An occurrence of powdery mildew disease on this tree was previously recorded in Argentina; however, in that study, the causal fungus was not identified (Mantz et al., 2008). Their description of the causal fungus was actually identical to the characteristics reported here. Therefore, we believe that their fungus was also E. aquilegiae.

\section{References}

Braun, U. 1987. A Monograph of the Erysiphales (Powdery Mildews). Beih. Z. Nova Hedwigia 89:1-700.

Farr, D. F. and Rossman, A. Y. 2011. Fungal databases, systematic mycology \& microbiology laboratory, ARS, USDA. Retrieved May 18, 2011, from http://nt.ars-grin.gov/fungaldatabases/.

Liberato, J. R. and Cunnington, J. H. 2006. First record of Erysiphe aquilegiae on a host outside the Ranunculaceae. Australas. Plant Path. 35:291-292.

Mantz, G., Ronco, L. and Monaco, C. 2008. First record in Argentina of powdery mildew of Casuarina cunninghamiana caused by Oidium sp. J. Plant Pathol. 90:397.

*Corresponding author (hdshin@korea.ac.kr) 